\title{
Math Learning Model that Accommodates Cognitive Style to Build Problem-Solving Skills
}

\author{
Warli $^{1} \&$ Mu'jizatin Fadiana ${ }^{1}$ \\ ${ }^{1}$ Mathematics Education Department, University Ronggolawe Tuban, Indonesia \\ Correspondence: Warli, Mathematics Education Department, University Ronggolawe Tuban, Indonesia. Tel: \\ 628-121-697-4878. E-mail: priyono.unu_sidoarjo@yahoo.com
}

Received: May 19, 2015

Accepted: June 23, 2015

Online Published: July 21, 2015

doi:10.5539/hes.v5n4p86

URL: http://dx.doi.org/10.5539/hes.v5n4p86

\begin{abstract}
The purpose of this research is to develop mathematical learning models that accommodate the cognitive styles reflective vs. impulsive students to build problem-solving skills, quality (valid, practical, and effective). To achieve the target would do research development (development research) and method development that consists of five stages, namely (1) the initial assessment phase, (2) design phase, (3) the stage of realization/construction, (4) stage of the test, evaluation and revision, and (5) the stage of implementation. To assess the quality of math learning model that accommodates cognitive styles reflective of the impulsive vs, used criteria valid, practical and effective. For testing the quality of models, conducted trials in SMP country 5 Tuban.

Based on the research results obtained mathematical learning models that accommodate the cognitive style consists of 6 phases. The term phase can be interpreted as measures of learning activities. Phase of this model are: (1) introduction, (2) the representation of mathematical concepts through realistic problems, (3) organizing the students in groups based on cognitive style reflective impulsive vs. (4) discussion of problem solving and presentation, (5) a problem-solving exercise (Evaluation), (6) cover.
\end{abstract}

Keywords: learning models, cognitive style, impulsive, reflective, problem solving

\section{Introduction}

According to the constructivist view, knowledge is actively constructed by the children is based upon the knowledge of cognitive structure of beginning or who have been previously owned. This means, we suggest that teachers must understand the cognitive structure of experience or owned children before, and understand how children construct knowledge. Davis, Maher and Noddings (1995) tell us that we have to help students develop in ways that are more powerful in thinking. We must give students "thinking tool" and not only are given the formulas and algorithms. Help "a tool to think" to be more effective, in accordance with the cognitive structures that are owned as well as according to the way children in building knowledge. While Confrey (1995) says that when the concepts of teaching as a form of communication, teachers should form a model that fits with the way students in looking at ideas and then have to help students in the restructure their views became more in line with students and in accordance with the perspective of the teacher. This is in line with Teng Fatt (2000) which says that ideally, the way teachers teach must comply with the way students learn. Some of the opinions indicated that teachers should be able to develop a model that suits the style of students in student learning. The problem, every student has a learning style/different cognitive styles.

Witkin et al. (1977) also defines that cognitive style is the vast dimensions of the self-consistency in the form of cognitive function, interlocking global dimension, which crosses the perceptual and intellectual domains, and domains that are also commonly understood as social behavior, personality, body, and the concept of Defense. Being Kogan (1973) defines cognitive style as individual variations in the way it feels, remembering, thinking, or as a way to distinguish, grasp, hold, incarnating, and utilize the information. This is in line with Liu and Ginther (1999) which suggests that cognitive style refers to the individual's characteristics and tendencies in feel, remember, organize, process, thinking, and problem-solving.

How the students in the study had a different style. Riding and Rayner (2005) said that the importance of awareness of the potential of this style to enhance and improve human performance in a variety of contexts. On cognitive style, do not use the term ability (cognitive ability) or intelligent. Santrock (2007) explains that learning 
styles and thinking skills, but the way is not chosen someone to use her ability. In line with the Riding and Rayner (2005) reveal that someone's style reflects the way in which a person accustomed to approaching or responding to the task of learning. Based on the opinion of cognitive style is the way a person thinks, are learning strategies are the attempts made to learners in the face demands of learning activities, so that when the charge is changed, then the learning strategy will be changed, but his cognitivestyle does not change. Firmer Riding and Rayner (2005) says that a person's cognitive style may be a way that built and automatically respond to the information and situation. This may exist from birth, or at any rate is fixed at the beginning of life and considered very pervasive so that affects various functions of the individual. A person's cognitive style is an aspect of a relatively fixed (Kagan, 1965; J. Kogan \& Kagan, 1970; Witkin et al., 1977; Salder-Smith \& Riding, 1999; Liu \& Ginther, 1999; Riding \& Rayner, 2005).

Cognitive style and learning style is often in the perception of the right the same, but some experts argue that the nature of the academic theory of cognitive styles are learning style is the practice. However, there are experts who say that learning styles are influenced by cognitive style, and learning styles will affect learning strategies learners. Salvisberg (2005) explains that a learning style refers to individual cognitive styles (i.e. the relationship between cognition and personality) in the context of education, shows how a person's preferred approach to new information. Curry (Salder \& Riding-Smith, 1999) classifies the cognitive style and learning style in terms of the three-tier model "onions", with each of the layers of the onion represents particular invalid constructs. This research shows that the inner layer (cognitive style), relatively fixed and affect the outer layer (instructional options).

Cognitive style that became the focus in the study of cognitive style is an impulsive vs reflective expressed Jerome Kagan in 1965 , citing cognitive styles reflective vs. cognitive style is an impulsive yet many earlier writers had already been examined and many of the cognitive style of reviewing. Kagan (1965) stated, "Succinctly, stated, the reflection-impulsivity dimension describes the child's consistent tendency to display slow or fast response times in problem situations with high response uncertainty.” J. Kogan and Kagan (1970) defines the reflective-impulsive is the degree/level of accuracy in describing the subject of the alleged problem resolution containing uncertain answers. Rozencwajg and Corroyer (2005) defines cognitive styles reflective of impulsiveness is the nature of the cognitive system which combines the time make decisions and work (performance) in solving their containing uncertainty (uncertainty) a high level.

So the child has a characteristic quick in answering a problem, but not/less carefully, so the answer is likely to be wrong, children like this is called cognitive-style impulsiveness. A child who has a characteristic slow in answering the problems, but careful/observant, so the answer is likely to be true, such a child is called cognitive style reflective (Warli, 2010b).

Some study cognitive styles reflective vs. impulsive in mathematics education, research results Warli (2009) about the thought process a reflective and impulsive children in solving problems of geometry concludes that: Reflective Students in problem-solving process performed in analytic. Reflective students very careful at this stage working on (many dabble first) pay attention to various aspects, so the answer is likely to be the correct value. Students who are less scrupulous impulsively on stage working on (a little dabble), right tackle, so the answer is likely to be wrong. Warli (2010a) research about children's math skills reflective and impulsive children meyimpulkan that: there is a significant difference between the math skills of students who are reflective and student cognitive style-style cognitive impulsivity. Cognitive style reflective of students showed better than math skills students are impulsive. Results of other studies conducted by the Warli (2010b) about the students creativity profile cognitive style reflective or impulsive in solving problems of geometry concludes that: reflective students creativity in problem solving geometry tends to be high, was an impulsive student creativity in solving geometry problems tend to be very low. And research Warli (2014) in logical thinking suggests that cognitive style reflective students who have the ability to find a truth based on rules of a particular pattern or logic, better than the students cognitive-style impulsiveness. Student cognitive style, impulsive lot made a mistake and less systematic in discovering a truth based on rules, patterns or logic, making it less effective in proving the truth.

Problem-solving ability becomes an important part that must be developed through learning. Every question is not necessarily a problem for students. According to Cooney et al. (1975, p. 242) “... for a question to be a problem, it must present a challenge that cannot be resolved by some routine Saturday procedure known to the student." This statement shows that not every question is a problem, tied to their students. This is emphasized by Schoenfeld (1985) which states, "The difficulty with defining the long-term problem is that problem solving is relative". While the trouble-shooting according to Polya (1980) is "... is finding the unknown distinctly conceived a means to end." Problem solving means finding a way, find a way out of the difficulty, discover how to overcome obstacles, to 
achieve the desired goal, with the appropriate tools. While Orton (1992) states, "Problem-solving is now normally intended to imply a process by which the learner combines previously learned elements of knowledge, rules, techniques, skills and concepts to provide a solution to a novel situation." Problem solving is a process which is done in the learning combines the knowledge components, rules, techniques, skills and concepts to produce a solution to the new situation. Measures mathematical problem solving often used as reference are the steps mentioned by Polya. Polya (1973) explained that the resolution contains four stages (phases) solution, namely 1) understand the problem (understanding the problem); 2) specify the plan (devising a plan); 3) executed as planned (carrying out the plan); 4) checks back (looking back). Next steps this will serve as the Polya reference to design worksheets students in developing the ability to solve math problems.

\section{Method}

\subsection{This Type of Research}

The purpose of this research is to develop mathematical learning models that accommodate the cognitive styles reflective vs. impulsively to improve problem-solving skills, then this kind of research including research development. The stages of the development of this learning model refers to the stages of development model expressed by Plomp (1997, pp. 6-15), namely (a) the initial assessment phase, design phase, (b), and (c) the stage of realization (construction), (d) the stage of testing, evaluation, and revision and (e) the stage of implementation. While the components covered in the model refers to the learning model components expressed Joice, Weil, and Shower (1992), namely (a) the syntax, (b) social system, (c) the principle of reaction, (d) support system, and (e) the impact of instructional and accompanist. Research activities will be undertaken to produce a mathematical model of learning which accommodates cognitive styles reflective of the impulsive vs is a method of research and development (Research and development).

The subject chosen grade VIII SMP country 5 Tuban, East Java that is reflective of the cognitive style and cognitive-style impulsiveness. Instrument to know cognitive styles reflective-impulsive, Warli (2010b) developed from tests made by Kagan (1965), the MFFT (Matching Familiar Figures Test). Based on the analysis results obtained a learner cognitive style is an impulsive 13 children (36.1\%) being reflective there are 12 children $(33.3 \%)$. The other learners have a quick and precise characteristics in thinking or slow and wrong. Further data will be done based on grouping based on cognitive style. Students who have speed and the accuracy of the thinking differently will help each other to achieve common goals and success in learning. Impulsive students will be helped by a reflective students who think more reflective, so it's not too fast in taking decisions. Likewise, students will be helped by a reflective impulsive, they will more quickly in thinking while maintaining the accuracy of his thinking. So in one group gives children consists of reflective and impulsive children.

\subsection{Data Analysis Techniques}

\section{Validity of Data Analysis Model}

The process of data analysis, the validity of this model is to determine which category the validity of any or all aspects of the criteria or aspects with early aspect criteria or average average or average total (X) using the following categories:

$$
\begin{aligned}
3,5 \leq \bar{X} \leq 4 & \text { very valid } \\
2,5 \leq \bar{X}<3,5 & \text { valid } \\
1,5 \leq \bar{X}<2,5 & \text { quite valid } \\
& \text { invalid }
\end{aligned}
$$

\subsection{Description: To Find the Overall Validity of the Aspects}

The criteria used to decide that learning mathematical model that accommodates cognitive styles reflective vs. impulsive has an adequate degree of validity is (i) value to the overall aspect of at least being in the category of "valid enough", and (ii) the mean value for each aspect of at least being in the category of "valid". If not, then the necessary revision based on the advice of the validity or by looking back on aspects that are worth less. Then restart the validation is performed and analyzed again. And so on to meet the minimum value of $\mathrm{M}$ is in the category is valid.

\subsection{Data Analysis of the Practicability of the Model}

The data obtained from the model practicality observation results implementation model is generally of two observers. As for activities performed in the process of implementation of the data model analysis is to determine which category the overall aspect or aspects of the the implementation of eachmodel by matching the average 
every aspect or average total aspect ( ) using the following

$1,0 \leq M<2,0$ resources were very low,

$2,0 \leq M<3,0$ resources were low,

$3,0 \leq M<4,0$ done medium.

$4,0 \leq M<5,0$ resources were high,

$\mathrm{M}=5 \quad$ resources were very high,

Description: $\mathrm{M}=$ to find the validity of every aspect,

$\mathrm{M}=$ to find the validity of the overall aspect.

The criteria used to decide that having a sufficient degree of implementation is the mean value of each aspect and the overall minimum set in the category were carried out in part, means that the model is not revised. If the value is in the other category, then the revision needs to be done with looking back on aspects that are worth less. Next up was done back in observation of the learning results of model revisions, then analyzed again, and so on to meet a minimal value.

\subsection{Data Analysis Model Effectiveness}

An analysis of the effectiveness of the model is supported by the results of the analysis of data from 4 components effectiveness, i.e.:

A student learning outcome analysis

1) Analysis of the mastery learning materials for mathematics

Analysis of the results of student learning is directed at the achievement of has been completedindividual and has been completed classical. If a student earns $\mathrm{S} \geq 6.5$ then students concerned reached has been completed individuals. If at least $85 \%$ of students achieved a score of at least 6.5 , then classical has been completed has been reached.

2) Analysis of the ability of mathematical problem solving

The analysis is performed against score-score obtained by students of math problem solving ability tests given at the end of the study. Whereas the achievement of learning outcomes generally said to be fulfilled if the three aforementioned aspects (has been completed learning, problem-solving ability standard) has been reached.

b) Data analysis activities students

Student activity observation results data for ongoing learning activities are analyzed and described. Calculate the mean frequency and the average percentage of time spent by students do activities for learning activities.

c) Data analysis, student response to the application of the Model

Student response to the implementation of the data model is divided into three aspects, namely (1) student response against learning, (2) student response to the students' books, and (3) the student response against LKS. Activities carried out to analyze the student response data in the relatively same three aspects, i.e. through the steps as follows. Specify the category for the positive response of students by matching a percentage of results by category as follows:

$3,5 \leq \bar{X} \leq 4$ The response was very positive

$2,5 \leq \bar{X}<3,5$ Positive response

$1,5 \leq \bar{X}<2,5$ The response was quite Positive

$0,5 \leq \bar{X}<1,5$ The response was less positive

$\bar{X}<0,5$ The response was not positive

The criteria set for declaring that the students have a positive response to the book, students, learning and LKS is more than $50 \%$ of them gave a positive response to at least $70 \%$ the number of aspects that are asked. Positive response of students to the application of mathematical learning model that accommodates cognitive styles reflective-impulsive is said to be reached when the criteria for a positive response to the three aspects of student (student book, learning, and LKS) is met.

d) Data analysis the management of Learning

Analysis of the results of assessment made against two observers who observed the ability of the teacher to manage 
learning model in the class. From the results of the second assessment determined the mean values of the observer, KG determination of intervals confirmed with further categories of teacher's ability to manage learning, namely:.

$$
\begin{aligned}
\mathrm{KG}<1,5 & \text { means very low } \\
1,5 \leq \mathrm{KG}<2,5 & \text { means low } \\
2,5 \leq \mathrm{KG}<3,5 & \text { mean enough/are } \\
3,5 \leq \mathrm{KG}<4,5 & \text { means high } \\
4,5 \leq \mathrm{KG} & \text { means very high. }
\end{aligned}
$$

The criteria used to decide that the ability of the teacher to manage learning adequate minimum POUNDS value is located in the high category means the appearance of teachers can be maintained. If the value of KG is in the other category, then the teacher must improve its ability to pay attention to the aspects of the return value is less. Next do re observation of teacher's ability to manage learning, then analyzed again. And so on to meet a minimal value of $\mathrm{KG}$ is in the high category.

\section{Analysis and Discussion}

\subsection{The Learning Model Design}

The stages of the development of this learning model refers to the stages of development model expressed by Plomp (1997, pp. 6-15) are only up to 4 stages, namely (a) the initial assessment phase, (b) design phase, and (c) the stage of realization (construction), and (d) the stage of testing, evaluation, and revision. While the components covered in the model refers to the learning model components expressed Joice, Weil, and Shower (1992), namely (a) the syntax, (b) social system, (c) the principle of reaction, (d) support system, and (e) the impact of instructional and accompanist.

Learning of mathematics cognitive styles that accommodate impulsive vs reflective approach implemented with cooperative to enhance problem-solving capabilities. Two cognitive styles students, namely reflective and impulsive combined with problem-solving and cooperative approach of Polya's mathematical learning in the right scenario in junior high to enhance problem-solving capabilities. Some modifications in the model of learning which will be developed based on studies and theories of learning and cognitive style theory of learning mathematics model is obtained as follows.

\section{a. Syntax}

The syntax for the learning of mathematics, which accommodates cognitive style consists of 6 phases. The term phase here refers to a term used Arends (1997). The term phase can be interpreted as measures of learning activities. Phase of this model are (1) introduction, (2) the representation of mathematical concepts through realistic problems, (3) organizing the students in groups based on cognitive style, (4) discussion of problem solving and presentation, (5) advanced troubleshooting exercise (Evaluation), (6) cover (Warli \& Fadiana, 2014). As for the details of each of the phases are presented in the following table.

The introductory phase, the teacher's activities are (1) organizing classes for learning, (2) form a measure of cognitive style (this is done only once, i.e., prior to learning), (3) convey the purpose of learning and provide motivation, (4) gives information about what the student will do, and (5) presents the issues related to the mathematical topics will be discussed. The representation of mathematical concept phase through realistic problems, activity teachers are (1) exposed the concept of mathematics based on issues that have been raised through the help of LKS, (2) randomly, giving the opportunity to the students to present the results of his work. Phases of organizing the students in groups based on cognitive style, teacher activities performed are (1) teacher form groups based on different cognitive styles, (2) in addition to cognitive style also consider the academic ability of students, (3) motivating students to work together to achieve success together. Phases of problem-solving discussions and presentations, the teacher's activity are: (1) give the opportunity to students to discuss understand math concepts more deeply especially in solving problems through the help of LKS, (2) randomly, giving the opportunity to the students to present the results of his work, (3) provide an opportunity to the students to respond to the results of other presentation of his friend, and discuss, (4) facilitating class discussion, and (5) guiding the students to work on and understand the problem correctly, and (6) provide reinforcement for the students who answered correctly, and provide guidance for students who answer have not been correct. Whereas the activities of teachers in advanced troubleshooting exercise phases (Evaluation) are (1) provide problem-solving questions, (2) give the opportunity to students to work on the problem and presents the results of its work in front of the class, (3) gives the opportunity to students to respond to the results of the work of his friend, (4) provide reinforcement for the students who answered correctly, and provide guidance for students who answer have not been correct. At the 
end of the study, teachers guide students to summarize the learning and provide advanced tasks (Warli \& Fadiana, 2014).

The syntax described above is a general pattern in an activity flow, and if there is an excess of meeting at a time, then before entering the closing phase, the teacher can go back on a problem-solving exercise continued phase, so onward.

\section{b. Social system}

In the mathematical study of cognitive style to accommodate the impulsive, reflective of the student who has the speed and the accuracy of the thinking differently will help each other to achieve the goal and success together. Impulsive students will be helped by a reflective, so that students will think more reflective, so it's not too fast in taking decisions. Likewise, students will be helped by a reflective impulsive, they will more quickly in thinking while maintaining the accuracy of his thinking. So both will co-exist weakness respectively. Interactions between students occurred during the discussion groups, and class discussion. At that time, students had the opportunity to collaborate, mutually defend each other's opinions, ask questions, help each other, and make agreements. While the role of the teacher is to guide, direct, and control his net discussion (Warli \& Fadiana, 2014).

\section{c. Principles of Management/Reaction}

Principles of learning with this model focuses more on (1) the principle of involving the students to be able to find math concepts with attention to cognitive style (speed and accuracy to think), (2) interaction with friends and teachers, as well as (3) the activity of the implementation of a job well done. In this model the teacher acting as a facilitator, motivator, mediator and consultant (Warli \& Fadiana, 2014).

\section{d. Supporting System}

The means necessary to implement this model, along with competent teachers also required some learning media. Other necessary support system is a learning device, i.e. learning implementation plan (RPP), the book students, student activity sheets (LKS), and the books teachers (Warli \& Fadiana, 2014).

\section{e. The impact of instructional and accompanist}

There are two models of this instructional impact. First, students can find and understand mathematical concepts through problem solving. Troubleshooting, used by teachers through the help of LKS to construct student understanding about a certain topic. Second, students can apply mathematical understanding of a particular topic. The impact is huge: (1) the students diligently, honestly and courageously expressed his opinion, (2) students are able to create and innovate in solving the problem, and (3) students to be sensitive to the environment, democratic and cooperative. The impact of this companion in tune with the social system that has been described above (Warli \& Fadiana, 2014).

\section{f. Organizing Learning}

In general organizing learning include organizing the activity, the activity of the students, teacher materials, and assignments. Organizing teachers' activities include (1) provision of a perception and motivation to students. This is done by explaining the existence of linkages between the materials studied with problem solving. (2) Teachers facilitate students to conduct discussions and presentations in appropriate problem-solving Polya. The main purpose of this is to get how to solve the problem. (3) Teachers facilitate students acquiring mathematical concepts. In this case the use of textbooks students and LKS are integrated. (4) Teachers facilitate students to apply math concepts in problem solving in accordance with learning objectives. (5) Teachers facilitate students to summarize the subject matter. And furthermore, give problems such as problem-solving exercises. Organizing student activity is carried out in two stages, namely (1) the activity of the group, and (2) individual events. Group activity carried out at a time when students discuss, i.e. when working discussions and presentations, while the activity individually, students at advanced training students (evaluation) (Warli \& Fadiana, 2014).

\section{Analysis of field trial results}

Next to see the quality of the models that have been composed, conducted field test in junior high SMP 5 Tuban. Math lessons in a week there is a SMP 5-hour lesson. In place of the research consists in 3 days, which is a Wednesday, Friday, and Saturday. In general the SMP 5 Tuban is one of the many school community in on faforit right Counties Tuban, East Java and is one of the schools was made in the implementation of the curriculum pilot 2013 in Indonesia. The quality of the model was tested using criteria from Nieveen (1999), which meet the valid, practical, and effective. Following consecutive analysis results 
a. Test the validity of the Model

To find out the validity of the model has been designed in the validation of the right to expert learning 2 (HS and RY). Validation results are then analyzed and revised according to the input of the valid. The results of analysis are presented in Table 2.

Table 2. Analysis of the results of the validation of content and invalid constructs model

\begin{tabular}{llll}
\hline \multirow{2}{*}{ No. } & Aspects That Are Assessed & \multicolumn{2}{l}{ Assessment Validator } \\
& Contents & Constructs \\
\hline 1 & Component Model & & 3,5 \\
2 & Support Theory & 4,4 & 4,0 \\
3 & Syntax & 4,3 & 4,6 \\
4 & Social System & 4,5 & 4,3 \\
5 & Reaction Principle Of Management & 4,5 & 4,8 \\
6 & Support System & 4,2 & 4,4 \\
7 & Instructional Impact And Impact Companion & 4,75 & 4,3 \\
8 & Implementation Of The Learning & 4,1 & 4,3 \\
9 & Learning Environment And Tasks Management & 4,8 & 4,1 \\
10 & Evaluation & 4,0 & 4,0 \\
& Equivalent & 4,4 & $\mathbf{4 , 2 3}$ \\
\hline
\end{tabular}

Based on the results of the validation analysis the contents of the model has been designed in a model means getting 4.4 has been designed to have the validation contents are valid. Results of the analysis of validation of the model that have invalid constructs designed on the model of the means obtained 4.23 have been designed to have the validation contents are valid. Nevertheless the author still had to revise some input from appropriate valid suggestion.

To know the to be valid learning device, then the device which has been designed in learning validation right to expert learning 2 (HS and RY) and 3 teachers (Elementary and Junior High School senior math teacher Qo N 3 Tuban, and ice senior Junior High School mathematics teacher N 5 Tuban). Validation results are then analyzed and revised according to the input of the valid.

Table 3. Analysis of the results of the validation of learning devices

\begin{tabular}{llll}
\hline No. & Aspects That Are Assessed & Equivalent Assessment Validator & Description \\
\hline 1. & Learning Plans & 4,6 & Valid \\
2. & Student's Book & 4,6 & Valid \\
3. & Teacher's Book & 4,6 & Valid \\
4. & Student Activity Sheets & 4,7 & Valid \\
5 & Problem Solving Test & 4,8 & Very valid \\
\hline
\end{tabular}

Based on the results of the analysis of validation of learning device on Table 3, indicates that the device is learning that has been designed to have the validity of either. Refer to the validation analysis results invalid constructs and content model validation analysis and learning device it can be concluded that the mathematical learning models that accommodate the cognitive styles reflective vs. impulsive already meet the to be valid model.

a. Test the practicality of the model

To observe the practicality of mathematics learning model that accommodates cognitive styles reflective vs. impulsively, then conducted the study by following the syntax model and supporting learning using a device model. Thus, observations of practicality model aimed at implementation the components of the model include supporting system components (the study). The data model is obtained from the practicality of observations implementation 
the model is generally of two observers. Each completed quis do reflection, it aims to fix the things that still need to be improved and improving an already good aspects. Analysis of every meeting (topic) can be shown in Table 4.

Table 4. The observations (assessment) implementation model

\begin{tabular}{lllllll}
\hline $\begin{array}{l}\text { Sunday } \\
\text { to }\end{array}$ & Learning Topics & Sintaxt & $\begin{array}{c}\text { System } \\
\text { Socials }\end{array}$ & $\begin{array}{c}\text { The Principle } \\
\text { of Reaction \& } \\
\text { Management }\end{array}$ & Equivalent & Description \\
\hline 1 & Specify the datum and data concepts & 3,3 & 3,25 & 3,6 & 3,38 & Medium \\
& Data Collection & 3,6 & 3,5 & 4,0 & 3,70 & Medium \\
2 & Data Processing & 3,6 & 4,0 & 4,0 & 3,86 & Medium \\
3 & Presentation Of Data & 4,3 & 4,0 & 4,6 & 4,30 & High \\
4 & Concepts Of Sample Space & 4,3 & 4,25 & 4,4 & 4,32 & High \\
& The Concept Of Opportunities & 4,3 & 4,5 & 4,6 & 4,47 & High \\
& Complementary Events & 4,3 & 4,5 & 4,4 & 4,4 & High \\
\hline
\end{tabular}

The observations in the first week were less encouraging, merely to implementation the level of being. Some of the results of the discussion between the teacher's notes and observers include (a) learners still impressed not relaxed, so that effective interaction does not occur, either as teachers convey information as well as discussion, (b) LAS when discussion groups provide less guidance on learners, so the discussion is less successful, (c) the discussions less effective, so don't look reflective and impulsive children's role as the individual characteristics of each. And a few small notes that its need of adaptation both teachers and learners model. Furthermore the result of reflection followed up with revisions to fix in the next study. Furthermore the result of reflection in week two, the third and fourth done similar things, so it looks in Table 4, the better the level of implementation.

Refer to the results of the analysis of the observation of implementation model can be inferred that the learning of mathematical model that accommodates cognitive styles reflective vs. impulsive meets practicality model.

a. Test of The effectiveness of the model

1) Learning management data analysis

Analysis of the results of assessment made against two observers who observed the ability of the teacher to manage learning math learning model that accommodates cognitive styles reflective vs. impulsive in class. Observations were made to the ability of the teacher to manage each phase in model syntax. From the results of the second assessment determined the mean values of the observer, KG from KG1 and KG2 KG1 = value with the average results of the assessment of the first observer and $\mathrm{KG} 2=$ value assessment results mean second observer. Analysis learning management savings results can the author serve at Table 5.

Table 5. Analysis of results of observations (assessment) learning management

\begin{tabular}{llllllllllll}
\hline $\begin{array}{l}\text { Sunday } \\
\text { to }\end{array}$ & Learning Topics & \multicolumn{3}{c}{ The Observations } & & & & & & Equivalent & Description \\
\hline \multirow{2}{*}{1} & Specify the datum and data & 3,2 & 3,0 & 4,0 & 3,7 & 3,5 & 4,2 & 3,4 & 4,2 & 3,6 & High \\
& concepts & & & & & & & & & & \\
& Data Collection & 3,2 & 3,25 & 4,25 & 3,5 & 3,5 & 4,6 & 4,4 & 4,2 & 3,9 & High \\
\multirow{2}{*}{2} & Data Processing & 4,2 & 3,5 & 4,5 & 4,2 & 4,0 & 4,5 & 4,6 & 4,2 & 4,2 & High \\
& Presentation Of Data & 3,8 & 4,25 & 4,5 & 4,6 & 4,0 & 4,4 & 4,6 & 3,8 & 4,2 & High \\
3 & Concepts Of Sample Space & 4,2 & 4,5 & 4,5 & 4,2 & 4,0 & 4,4 & 4,8 & 4,2 & 4,3 & High \\
4 & The Concept Of Opportunities & 4,6 & 3,75 & 4,5 & 4,2 & 4,5 & 4,6 & 4,8 & 4,6 & 4,4 & High \\
& Complementary Events & 4,2 & 4,5 & 4,5 & 4,5 & 4,5 & 4,6 & 4,8 & 4,4 & 4,5 & High \\
\hline
\end{tabular}


Description: F1, F2: Introduction: the representation of mathematical concepts through realistic problems, F3: Organize students into groups based on cognitive style, F4: problem-solving discussions and presentations, F5: practice solving advanced (Evaluation), F6: cover, W: Time Management, and S. K.: an atmosphere of class.

Refer to Table 5, looks at the topic of learning data and concepts define the Datum and the meeting topic data collection although final results management of high learning. But if you take there are still aspects that are still below the 3.5 (medium). For that discussion needs to be done (reflection) for further revision on aspects that are less good. And in week 4, the result is a high category.

1) Data analysis, student response to the application of the model

Student response data on the application of mathematical learning model that accommodates cognitive styles reflective vs impulsivity divided into three aspects, namely (1) student response against learning, (2) student response to the students' books, and (3) the student response against LKS. Now student response was given only one time in a week, after the completion of quis. Here the author serve at Table 6.

Table 6. The application of learner response model

\begin{tabular}{|c|c|c|c|c|c|c|c|c|c|}
\hline \multirow{2}{*}{ No. } & \multirow{2}{*}{ Aspect } & \multicolumn{4}{|c|}{ Sunday to } & \multicolumn{4}{|c|}{ Sunday to } \\
\hline & & 1 & 2 & 3 & 4 & 1 & 2 & 3 & 4 \\
\hline \multirow{8}{*}{ I } & & \multicolumn{4}{|c|}{ Happy (\%) } & \multicolumn{4}{|c|}{ Not happy (\%) } \\
\hline & \multicolumn{9}{|l|}{ How you feel towards: } \\
\hline & 1. Subject matter & 54 & 62 & 78 & 84 & 46 & 38 & 22 & 16 \\
\hline & 2. Student's book & 76 & 78 & 83 & 94 & 24 & 22 & 17 & 6 \\
\hline & 3. Student worksheet (LKS) & 52 & 58 & 80 & 81 & 48 & 42 & 20 & 19 \\
\hline & 4. The atmosphere of learning in the classroom & 63 & 76 & 86 & 92 & 37 & 24 & 14 & 8 \\
\hline & 5. The way teachers teach & 76 & 80 & 84 & 88 & 24 & 20 & 16 & 12 \\
\hline & & \multicolumn{4}{|c|}{ New $(\%)$} & \multicolumn{4}{|c|}{ Not happy (\%) } \\
\hline \multirow{4}{*}{ II } & What do you think of the : & & & & & & & & \\
\hline & 1. The Subject Matter & 67 & 76 & 85 & 91 & 33 & 24 & 15 & 9 \\
\hline & 2. Student's book & 64 & 78 & 84 & 89 & 36 & 22 & 16 & 11 \\
\hline & & \multicolumn{4}{|c|}{ Interest (\%) } & \multicolumn{4}{|c|}{ No mood $(\%)$} \\
\hline III & $\begin{array}{l}\text { Are you interested in further learning activities } \\
\text { like follow you follow? }\end{array}$ & 72 & 78 & 87 & 94 & 28 & 22 & 13 & 6 \\
\hline \multirow[t]{2}{*}{ IV } & $\begin{array}{l}\text { Do you think about the book the student and the } \\
\text { student Worksheet (LKS) }\end{array}$ & 62 & 73 & 81 & 88 & 38 & 27 & 19 & 12 \\
\hline & & 65,1 & 73,2 & 83,1 & 89,0 & 34,9 & 26,8 & 16,9 & 11,0 \\
\hline
\end{tabular}

The criteria set for declaring that the students have a positive response to the book, students, learning and LKS is more than $50 \%$ of them gave a positive response to at least $70 \%$ the number of aspects that are asked. See Table 6 above, after the meeting in the second week already meet more than $50 \%$ of them gave a positive response to at least $70 \%$ the number of aspects that are asked. Based on the data in Table 6, the criteria of a positive response to the three aspects of student (student book, learning, and LKS) is met, so the student response to the application of mathematical learning model that accommodates cognitive styles reflective-impulsive is positive.

1) Data analysis activities of teachers and students

For student observation activities focus on two groups; the first group, impulsive and 2 kids 3 reflective. The second group, 3 children 2 reflective and impulsive. The two groups of election considerations (a) observations in order to better focus, (b) the selected group level has a conclusion and to reflective high. In the fourth week of the better the students events, every aspect is assessed as effective, though it still has not met the ideal time. Here the authors presented results of the analysis of activity of the fourth week on the Table 7. 
Table 7. Table of activities teachers and students during the fourth week of learning

\begin{tabular}{lllll}
\hline No & The Types Of Activities & $\begin{array}{l}\text { The Range of } \\
\text { Effectiveness }\end{array}$ & Equivalent & Description \\
\hline \multicolumn{2}{l}{ Teacher Activity } & & & \\
1 & Explain/give information (problems) & $20 \%-30 \%$ & $26,6 \%$ & effective \\
2 & Observe the student activities & $15 \%-25 \%$ & $18,3 \%$ & effective \\
3 & Motivating students & $10 \%-20 \%$ & $13,2 \%$ & effective \\
4 & Hints/guide activities & $35 \%-45 \%$ & $41,7 \%$ & effective \\
5 & Behavior that is not relevant to the activitiesKBM & $0 \%-5 \%$ & $0,2 \%$ & effective \\
Aktivitas Siswa & & & \\
1 & Listen/pay attention to teacher/friend. & $20 \%-30 \%$ & $26,2 \%$ & effective \\
2 & Reading (books, Students or LKS) & $10 \%-20 \%$ & $17,2 \%$ & effective \\
3 & Writing that is relevant to KBM & $25 \%-35 \%$ & $27,2 \%$ & effective \\
4 & Discuss/ask between students and teachers & $25 \%-35 \%$ & $28,8 \%$ & effective \\
5 & throughout between the student and the student's & & & \\
& Behavior that is not relevant to KBM & $0 \%-5 \%$ & $0,6 \%$ & effective \\
\hline
\end{tabular}

1) Analysis of the ability of mathematical problem solving

The analysis is performed against score-score obtained by students of math problem solving ability tests given at the end of the study. The analysis is performed against score-score gained students from problem-solving ability test given after all the material thoroughly discussed. Analysis of the results of student learning is directed at the achievement of an individual and thorough disclosure to into an absolutely classical space. If a student earns $\mathrm{S} \geq 65$ then the concerned students achieve mastery over an individual. If at least $85 \%$ of students achieved a score of at least 65 , then to an absolutely classical space has been reached. Tests are conducted on a weekly basis, its analysis and the author serve at Table 8 .

Table 8. Description of problem-solving ability test results

\begin{tabular}{lllll}
\hline The Quis-i & Min. Value & Mak Value & Equivalent & Prosentasi Value $>65$ \\
\hline 1 & 41,18 & 94,12 & 71,73 & $63,89 \%$ \\
2 & 61,54 & 92,31 & 79,06 & $86,11 \%$ \\
3 & 36,84 & 94,74 & 76,75 & $83,33 \%$ \\
4 & 57,89 & 94,74 & 80,55 & $86,11 \%$ \\
\hline
\end{tabular}

See Table 8 . In quis to 1 , has not met to the satisfaction of a classical, and to complete a classical recently achieved on the quis 2 and quis to 4 . So at the last meet onto quis comprehensive classical space.

In looking closely at problem-solving ability, the author tried to observe the group that became the focus of observation (two groups). The two groups include reflective and 5 children 5 children impulsively. Based on the value of the equivalent of four quis impulsive child committed, experienced an increase in the ability of even insignificant. This shows that children are impulsive, when discussion can improve accuracy in thinking before taking a decision. However for reflective, accuracy becomes slightly decline, although there are still within the limits of the tool, which is good. The following authors are presented in Figure 1. 


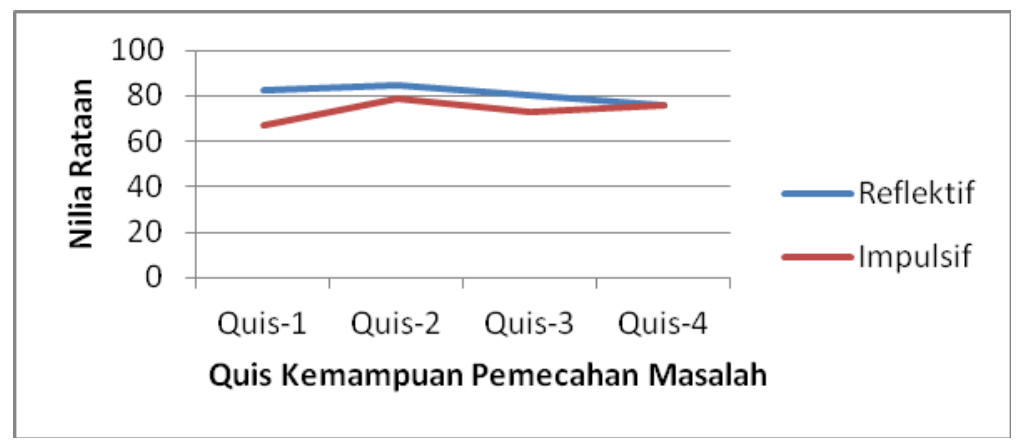

Figure 1. Problem-solving ability and reflective child impulsive

Refer to the results of the analysis of the management learning, student response to the learning model, the analysis of the activity of the students and teachers and problem-solving ability test results it can be concluded that the mathematical learning models that accommodate the cognitive styles reflective vs. impulsive already meet the effectiveness model. And based on the test results the test validity, practicality, and test the effectiveness of the model can be said that the learning of mathematical model that accommodates cognitive styles reflective vs. impulsively to build problem-solving skills are good models qualifies.

This learning model is like a cross between a model learning cooperative (cooperative learning), problem-based learning (problem based learning), learning and direct (direct instructional). Such a cooperative learning model (Arends, 1997, pp. 111-114), because of this learning model using the setting groups (discussion group), with the group that accommodate children's cognitive style. This is according to the constructivist view to assist in building the knowledge according to their style, but still help each other on their respective weaknesses. Problem-based learning models such as (Arends, 1997, pp. 158-161), because of this learning model using a realistic problem as the initial step in the understanding of mathematical concepts. It is also in line with the realistic approach to mathematics education. And this model as well as direct learning model (Arends, 1997, pp. 65-67), for this learning model using problem-solving exercises to strengthen children's understanding in developing problem-solving skills.

\section{Conclusion}

Based on the results of the analysis it can be concluded that the mathematical learning models that accommodate the cognitive styles reflective vs. impulsively to build problem-solving skills already comply with the quality of a good model (valid, practical and effective). As for the phase model is as follows.

Phase 1: introduction, activity teachers are:

1) organized classes to study,

2) cognitive style measure forms (this is done only once, i.e., prior to learning),

3) convey the purpose of learning and provide motivation,

4) gives information about what the student will do, and

5) lays out the problems associated with the mathematical topics will be discussed.

Phase 2: presentation of mathematical concepts through realistic problems, the activities of the teachers:

1) presents mathematical concepts based on issues that have been raised through the help of LKS,

2) randomly, giving the opportunity to the students to present the results of his work,

Phase 3: organize students into groups based on cognitive style, teacher activities performed are:

1) teachers forming groups based on different cognitive styles,

2) in addition to cognitive style also consider students' academic ability,

3) motivate students to work together to achieve success together.

Phase 4: problem-solving discussions and presentations, the teacher's activity are:

1) gives the opportunity to students to understand math concepts to discuss more in depth, especially in solving problems through the help of LKS, 
2) randomly, giving the opportunity to the students to present the results of his work,

3) provided an opportunity to the students to respond to the results of other presentation of his friend, and discuss,

4) facilitates class discussions, and

5) guiding students to work on and understand the problem correctly, and

6) provide reinforcement for the students who answered correctly, and provide guidance for students who answer have not been correct.

Phase 5: practice solving advanced (evaluation) are:

1) gives problems such as problem solving,

2) gives the opportunity to students to work on the problem and presents the results of its work in front of the class,

3) gives the opportunity to students to respond to the results of the work of his friend,

4) provide reinforcement for the students who answered correctly, and provide guidance for students who answer have not been correct.

Phase 6: cover, the end of learning activities, teachers guide students to summarize learning, do reflection and provide advanced tasks.

Measurement of cognitive style is only done once, then not performed measurements, because of cognitive style are fixed.

\section{Acknowledgments}

The authors thank the DP2M Director General of higher education who have given funds research to finish, and the valid has been giving a lot of advice and input.

\section{References}

Alan, H. S. (1985). Mathematical Problem Solving. New York: Academic Press Inc.

Arends, R. I. (1997). Classroom Instruction and Management. New York: McGrawhill Companies Inc.

Confrey, J. (1995). What constructivism implies for teaching. Journal for Research in Mathematics Education, 107-122.

Cooney, T. J., Davis, E. J., \& Henderson, K. B. (1975). Dynamics of Teaching Secondary School Mathematics. Boston: Houghton Mifllin Company.

Davis, R. B., Carolyn, M. A., \& Noddings, N. (1995). Suggestions for the Improvement of Mathematics Education. Journal for Research in Mathematics Education, 187-191.

Joyce, B., Weil, M., \& Showers, B. (1992). Models of Teaching (4th ed.). Boston: Allyn \& Bacon.

Kagan, J. (1965). Reflective and Impulsive Children: Significance of Conceptual Tempo. In J. D. Krumboltz (Ed.), Learning and the Educational Process. Chicogo: Rand Mc Nally \& Company.

Kagan, J., \& Kogan, N. (1970). Individual Variation in Cognitive Process. In P. Mussen (Ed.), Carmichael's Manual of Child Psychology (3rd ed., Vol. 1). New York: Wiley.

Liu, Y. L., \& Ginther, D. (1999). Cognitive Style and Distance Education. Online Journal of Distance Learning Administration, 2(3). State University of Georgia.

Nieveen, N. (1999). Prototyping to Reach Product Quality. In J. V. D. Akker, R. M. Branch, K. G. Nieveen, \& T. J. Plomp (Eds.), Design Approaches and Tools in Education and Training (pp. 125-135). Kluwer Academic Publishers, Dordrecht, the Netherlands. http://dx.doi.org/10.1007/978-94-011-4255-7_10

Orton, A. (1992). Learning Mathematics. Issues, Theory and Classroom Practice (2nd ed.). Printed and bound in Great Britain by Dotesios Ltd. Trowbrigde, Wilts.

Poly, A. G. (1973). How to Solve It (2nd ed.). Princeton, New Jersey: Princeton University Press.

Poly, A. G. (1980). On Mathematical Problem Solving in High School. In K. Stephen, \& R. Robert. (Eds.), Problem Solving in School Mathematics. Reston, Virginia: NCTM Inc.

Riding, R. R., \& Stephen. (2005). Cognitive Style and Learning Strategies Understanding Differences in Learning Style and Behaviour. Canada: David Fulton Publishers.

Rozencwajg, P., \& Corroyer, D. (2005). Cognitive Processes in the Reflective-Impulsive Cognitive Style. The Journal of Genetic Psychology, 166(4), 451-463. http://dx.doi.org/10.3200/GNTP.166.4.451-466 
Sadler-Smith, E., \& Riding, R. (1999). Cognitive Styles and Instructional Preferences. Instructional Science, 27, 355-371. http://dx.doi.org/10.1007/BF00892031

Salvisberg, J. A. (2005). Cognitive Style and Learning Strategies. IATEFL ISSUES.

Santrock, J. D. (2007). Psychology of Education (2nd ed.). Interpreting, Tri Wibisono B.S. Jakarta: Kencana.

Teng, F., \& James, P. (2000). Understanding the Learning Styles of Students: Implications for Educators. The International Journal of Sociology and Social Policy 20, 11(12), 31-45.

Tjeerd, P. (1997). Educational and Training System Design. Enschede, The Netherlands: Univercity of Twente.

Warli, \& Fadiana, M. (2014). Design of Mathematic Learning Based on Cognitive Style. Proceedings International Conference on Research, Implementation and Education of Mathematics and Sciences, 2014. Yogyakarta State University.

Warli. (2009). The process of thinking and Reflective Child Impulsive Child in solving geometry problems. Paedagogi. Journal of education and science, 5(2), 40-56.

Warli. (2010a). Math skills children are Reflective and Impulsive Children. Proceedings of the National Seminar on mathematics and mathematics education in UMM Unfortunate Date 30-1-2010.

Warli. (2010b). Profile Creativity Cognitive style Reflective Students and student Cognitive style Impulsiveness in solving geometry problems. Dissertation PPS UNESA Surabaya.

Warli. (2014). The ability of logical thinking Student Cognitive style Reflective vs. Impulsive. Proceedings of the National Seminar on mathematics, Mathematical and statistical Education.

Witkin, H. A., Moore, C., Goodenough, D. R., \& Cox, P. W. (1977). Field dependent and Field independent Cognitive Styles and Their Educational Implication. Review of Educational Research, 47, 1-64. http://dx.doi.org/10.3102/00346543047001001

\section{Copyrights}

Copyright for this article is retained by the author(s), with first publication rights granted to the journal.

This is an open-access article distributed under the terms and conditions of the Creative Commons Attribution license (http://creativecommons.org/licenses/by/3.0/). 